\title{
LAS ELECCIONES ITALIANAS BAJO EL FUEGO DE LA CRITICA
}

\section{ITALIA, LABORATORIO POLITICO}

No es la primera vez que los acontecimientos políticos de Italia manifiestan extraordinario interés para la teoría y práctica políticas.

Las recientes elecciones generales en dicho país lo corroboran: los resultados electorales, la crisis de su sistema de partidos, la inestabilidad política, la pérdida de entusiasmo cívico y el desencanto político, son datos suficientemente significativos.

Italia es un laboratorio político espléndido. Los análisis que los observadores nacionales y extranjeros hacen sobre la vida política italiana son numerosos y agudos. Su interés para España, donde comienzan a darse efectos semejantes, es evidente. ¿Podremos aplicar remedios efectivos, si los hay, para consolidar nuestra incipiente democracia, a la vista del caso italiano?

\section{UNAS ELECCIONES SUPERFLUAS}

El presidente de la República tuvo motivos suficientes para disolver anticipadamente las Cámaras; el Partido Comunista estaba interesado en las elecciones para comprobar su efectiva potencialidad, para concretar la posibilidad de entrar en un Gobierno de unidad y realizar el compromiso histórico. La Democracia Cristiana deseaba conocer todos esos extremos; sin embargo, parece que la consulta electoral ha sido inútil.

El electorado se ha mantenido estable en líneas generales porque las variaciones no han superado del 2 al 3 por 100. El abstencionismo, los votos nulos y en blanco han aumentado respecto a 1976.

La crisis de la democracia italiana es clara. ¿Habrá otra disolución anticipada, próximamente, con resultados semejantes? ¿En qué medida su reiteración no enervará, más aún, al electorado y debilitará al sistema establecido?

\section{EL PROBLEMA DE LA DEMOCRACIA ITALIANA}

La problemática política de Italia - coinciden gran parte de los analistas de dicho país- no estriba sólo en calcular el porcentaje de mayorías y minorías si- 
guiendo el crecimiento, disminución y transvase de votos, porque los partidos mayoritarios han sufrido quebrantos, más significativamente el PCI; la DC ha mantenido, con ligeras pérdidas, su posición y el PSI no ha crecido como esperaba.

El cansancio y desencanto del cuerpo electoral motivado por el pactismo entre los dos grandes; la rutina y falta de imaginación de sus líderes y programas, son hechos graves para la democracia italiana.

Los partidos interpuestos, PSDI, PRI, han tenido éxito en perjuicio sobre todo del PCI, aunque al PSI corresponde, venciendo perplejidades y clarificando su estrategia, decidir su apoyo a la DC o alinearse con el PCI.

Las minorías se han fortificado, incluidas las extraparlamentarias, dentro de los límites que permite el sistema electoral.

Mientras las fuerzas sindicales muestran su desilusión, los empresarios de la Confindustria y de la Confiagraria no disimulan su satisfacción.

El problema de la democracia italiana es la falta de líderes de talla, de estadistas reconocidos, de partidos y de programas que arrastren al elevado número de abstencionistas, de votantes en blanco y nulos. Causas morales, sociales, económicas e institucionales, interrelacionadas, condicionan aquella problemática.

\section{EL TERCER PARTIDO DE ITALIA: EL «PASBN»}

Uno de cada cinco italianos no ha votado o su papeleta ha sido en blanco o anulada. Entre abstenciones, votos nulos y en blanco se cuentan seis millones de ciudadanos.

El abstencionismo electoral italiano es un hecho grave, sobre todo teniendo en cuenta que antes las votaciones solían ser masivas.

La crisis del sistema de partidos, el desencanto popular producido por el pactismo DC-PCI extramuros del Parlamento, ha castigado, sobre todo, a estas dos formaciones políticas.

El abstencionismo político es un fenómeno grave que evidencia la crisis de la democracia. Frente a las posiciones mantenidas por varios politólogos norteamericanos sobre el óptimo participativo que desconfían de una elevada participación electoral, porque dicen que es síntoma de excesiva politización, enfrentamiento, etcétera..., hay que subrayar la conveniencia de una amplia concurrencia a las urnas.

Luigi Barzini sostiene - con cierta agudeza - que el tercer partido italiano es el «PASBN» (Partido del abstencionismo, de los votos en blanco y nulos). Sus hipotéticos parlamentarios serían casi 90 y si se aliasen a la DC formarían mayoría suficiente para gobernar. El «PASBN» supera en más de dos millones al PSI.

EI «PASBN» no es fascistoide, ni pasota, ni potencial seguidor de los grandes partidos de izquierda. Critica el sistema actual de partidos y su correspondiente práctica.

\section{CRisis DEL SISTEMa de PARTidos}

En este laboratorio político extraordinario que es Italia se confirma la crisis del sistema de partidos. Sus causas son muchas y complejas. He aquí algunas:

a) La norteamericanización de los partidos, que comienza a advertirse en España: interesa sólo el máximo resultado electoral, ganar votos a cualquier precio. Se potencia la organización y maquinaria partidista en perjuicio de la ideología y de una orientación política clara y coherente acerca de los problemas básicos de la comunidad. 
b) El fracaso de la bipolarización (DC-PCI) sin perjuicio de numerosos consensos y cambalaches.

c) La ausencia de líderes nacionales de partido pero sobre los partidos. En este sentido, el asesinato de Aldo Moro fue un golpe no sólo al corazón del Estado, sino además a la entraña de la democracia.

d) La rutinización y aburrimiento por la retórica y comportamiento partidistas.

Todo ello explica el éxito del Partido Radical como novedad interesante que ha restado votos al PCI, atraído el apoyo del electorado juvenil y explotado inteligentemente a su favor el descontento popular. En cambio, se afirma unánimemente que el PSI «ha sacudido el árbol pero sus frutos los han recogido otros».

Mientras los partidos italianos no acorten sus distancias con el pueblo, mientras sigan sucumbiendo a la tentación de ser empresas consumidoras de votos, cosa propia de las sociedades neocapitalistas, la democracia en Italia no será estable. Dicho de otro modo: ni en Italia, ni en España, se dan todavía como en Estados Unidos, en los Países Escandinavos y Alemania Federal, las condiciones de un neocapitalismo sólidamente establecido que permita partidos-empresas devoradores de votos. El neocapitalismo italiano y el español son inestables, dependientes estrictamente del exterior; están en crisis.

Tales partidos inmaduros, corrompidos y con líderes de escasa visión, que no contemplan la vida política con amplia óptica de estadistas, reproducen la crisis socioeconómica en el ámbito institucional y en la orientación política.

\section{FRACASO DE LOS INSTITUTOS DEMOSCOPICOS E ILUSION DESMESURADA SOBRE LA EFICACIA DE LOS ANALISIS POLITOLOGICOS}

Este laboratorio político italiano -y mutatis mutandis el español- no reproducen las condiciones estructurales, ni psicológicas, del norteamericano.

Parece que las predicciones demoscópicas han manifestado con estadísticas, cómputos y tabulaciones, evidencias de sentido común que ponen en tela de juicio la utilidad de los sondeos y predicciones electorales. El discurso sobre este punto no cabe en los rigurosos límites que han impuesto a este análisis. Lo lamento porque el tema es interesantísimo.

Numerosos estudiosos italianos han señalado la obsesión sobre los porcentajes que desconoce los cambios de mentalidad y de voto de un electorado fluido (Matteucci), la crítica de una società occupata y parcelada por los dos grandes partidos que controlan los centros decisorios (Ferrarotti). Italia tiene un sistema de partidos que no conecta, fielmente, con las variadas corrientes y subcorrientes de opinión.

Por otro lado, líderes de los partidos interpuestos (PL, PSDI) han criticado los entes dedicados a sondeos y predicciones electorales.

Los institutos demoscópicos, los politólogos made in USA, cuentan con un suculento material estadístico para apoyar sus consideraciones sobre el fenómeno electoral italiano, pero incurren en un auténtico nominalismo político: o sus reflexiones corroboran lo que se sabía de antemano, o han cometido notorios errores. Además, no han percibido aspectos relevantes.

Las elecciones italianas, bajo el fuego de la crítica, enseñan que es inoperante analizarlas trasplantando, mecánicamente, métodos y técnicas que no captan la vida política.

Este estupendo laboratorio italiano para el estudio de la fenomenología política evidencia: 
a) La escasa tradición democrática del país.

b) La persistencia de notables desniveles socioeconómicos.

c) La corrupción, no compensada con éxitos suficientes de la clase política, o sea, corrupción incompetente.

d) La volubilidad y fluidez de un electorado muy sensibilizado por la inoperancia de la clase política.

e) La crisis del sistema de partidos.

f) La enorme capacidad crítica del pueblo italiano combinada con el apasionamiento latino, que le impulsa a pasar, rápidamente, de momentos de euforia y entusiasmo cívicos, a otros de desencanto y anarquía.

g) El ingrediente del terrorismo utópico con sus proyectos de contracultura, de contrademocracia y de lucha fanática contra lo establecido.

¿Cómo pueden reducirse todas estas significativas variables a guarismos, tabulaciones y predicciones?

Quien pretenda conocer bien, y en profundidad, la vida política italiana, deberá matizar muchísimo los datos ofrecidos por los institutos de opinión pública y los análisis politológicos de influjo norteamericano. La idiosincrasia italiana, las tensiones variadas que se dan en su sociedad, las diferencias regionales, la contraposición laicismo-confesionalidad aún latente; la persistencia de un partido democristiano bastante corrompido; el eurocomunismo; los grupos extraparlamentarios, etc., son demasiados hechos que se rebelan a un tratamiento sofisticado o a una mera acumulación factualista. Hay que interpretarlos en su nivel correspondiente. Al triturarlos con las computadoras se volatiliza su mensaje profundo.

P. L. V. 


\begin{tabular}{|c|c|c|c|c|c|c|c|c|c|c|c|c|}
\hline \multicolumn{2}{|c|}{$\begin{array}{l}\text { CÁmARA DE } \\
\text { DIPUTADOS }\end{array}$} & \multirow{2}{*}{$\frac{\text { Radicales }}{-}$} & $\frac{\mathrm{PCI}}{18,9}$ & $\frac{\text { PSI }}{20,7}$ & \multirow{2}{*}{$\frac{\text { PSDI }}{-}$} & \multirow{2}{*}{$\frac{\text { PRI }}{4,4}$} & \multirow{2}{*}{$\begin{array}{l}\text { DCI } \\
35,2\end{array}$} & \multirow{2}{*}{$\frac{\text { PLI }}{6,8}$} & \multirow{2}{*}{$\begin{array}{c}\text { MON } \\
2,8 \\
16\end{array}$} & \multirow{2}{*}{$\begin{array}{c}\text { UQ-MSI } \\
5,3 \\
30\end{array}$} & \multirow{2}{*}{$\begin{array}{c}\begin{array}{c}\text { Otros } y \\
\text { regionales }\end{array} \\
\begin{array}{c}5,9 \\
20\end{array}\end{array}$} & \multirow{2}{*}{$\begin{array}{c}\begin{array}{c}\text { TOTAL } \\
\text { ESCANOOS }\end{array} \\
556\end{array}$} \\
\hline 1946 & $\begin{array}{r}\% \\
\text { Esc. }\end{array}$ & & $\begin{array}{l}18,9 \\
104\end{array}$ & $\begin{array}{l}20,7 \\
115\end{array}$ & & & & & & & & \\
\hline 1948 & & - & & & $\begin{array}{r}7,1 \\
33\end{array}$ & $\begin{array}{c}2,5 \\
9\end{array}$ & $\begin{array}{l}48,5 \\
304\end{array}$ & $\begin{array}{l}3,8 \\
19\end{array}$ & $\begin{array}{l}2,8 \\
14\end{array}$ & $\begin{array}{c}2,0 \\
6\end{array}$ & $\begin{array}{r}2,3 \\
6\end{array}$ & 574 \\
\hline 1953 & & - & $\begin{array}{l}22,6 \\
143\end{array}$ & $\begin{array}{c}12,7 \\
75\end{array}$ & $\begin{array}{r}4,5 \\
19\end{array}$ & $\begin{array}{c}1,6 \\
5\end{array}$ & $\begin{array}{l}40,1 \\
263\end{array}$ & $\begin{array}{l}3,0 \\
13\end{array}$ & $\begin{array}{l}6,9 \\
40\end{array}$ & $\begin{array}{l}5,8 \\
29\end{array}$ & $\begin{array}{r}2,8 \\
3\end{array}$ & 590 \\
\hline 1958 & & - & $\begin{array}{l}22,7 \\
140\end{array}$ & $\begin{array}{c}14,2 \\
84\end{array}$ & $\begin{array}{r}4,5 \\
23\end{array}$ & $\begin{array}{c}1,4 \\
6\end{array}$ & $\begin{array}{l}42,4 \\
273\end{array}$ & $\begin{array}{l}3,5 \\
14\end{array}$ & $\begin{array}{l}4,8 \\
25\end{array}$ & $\begin{array}{l}4,8 \\
25\end{array}$ & $\begin{array}{r}1,7 \\
6\end{array}$ & 596 \\
\hline 1963 & & - & $\begin{array}{l}25,3 \\
166\end{array}$ & $\begin{array}{c}13,8 \\
87\end{array}$ & $\begin{array}{r}6,1 \\
33\end{array}$ & $\begin{array}{c}1,4 \\
6\end{array}$ & $\begin{array}{l}38,3 \\
260\end{array}$ & $\begin{array}{l}7,0 \\
39\end{array}$ & $\begin{array}{c}1,7 \\
8\end{array}$ & $\begin{array}{l}5,1 \\
27\end{array}$ & $\begin{array}{r}1,3 \\
4\end{array}$ & 630 \\
\hline 1968 & & - & $\begin{array}{l}26,9 \\
177\end{array}$ & & & $\begin{array}{c}2,0 \\
9\end{array}$ & $\begin{array}{l}39,1 \\
266\end{array}$ & $\begin{array}{l}5,8 \\
31\end{array}$ & $\begin{array}{c}1,3 \\
6\end{array}$ & $\begin{array}{l}4,5 \\
23\end{array}$ & $\begin{array}{r}5,9 \\
26\end{array}$ & 629 \\
\hline 1972 & & - & $\begin{array}{l}27,2 \\
179\end{array}$ & $\begin{array}{l}9,6 \\
61\end{array}$ & $\begin{array}{r}5,1 \\
29\end{array}$ & $\begin{array}{l}2,9 \\
14\end{array}$ & $\begin{array}{l}38,8 \\
267\end{array}$ & $\begin{array}{l}3,9 \\
21\end{array}$ & - & $\begin{array}{l}8,7 \\
56\end{array}$ & $\begin{array}{r}3,8 \\
3\end{array}$ & 630 \\
\hline 1976 & & $\begin{array}{r}1,1 \\
4\end{array}$ & $\begin{array}{l}34,4 \\
227\end{array}$ & $\begin{array}{l}9,6 \\
57\end{array}$ & $\begin{array}{r}3,4 \\
15\end{array}$ & $\begin{array}{l}3,1 \\
14\end{array}$ & $\begin{array}{l}38,7 \\
263\end{array}$ & $\begin{array}{c}1,3 \\
5\end{array}$ & - & $\begin{array}{l}6,1 \\
35\end{array}$ & $\begin{array}{r}2,3 \\
10\end{array}$ & 630 \\
\hline 1979 & & $\begin{array}{c}3,4 \\
18\end{array}$ & $\begin{array}{l}30,4 \\
201\end{array}$ & $\begin{array}{l}9,8 \\
62\end{array}$ & $\begin{array}{c}3,8 \\
20\end{array}$ & $\begin{array}{l}3,0 \\
16\end{array}$ & $\begin{array}{l}38,3 \\
262\end{array}$ & $\begin{array}{c}1,9 \\
9\end{array}$ & - & $\begin{array}{l}5,3 \\
30\end{array}$ & $\begin{array}{l}4,1^{2} \\
12\end{array}$ & 630 \\
\hline
\end{tabular}

1 PSIUP $=4,5 \%$ y 23 escaños.

2 PDUP $=1,4 \%$ y 6 escaños.

FuENTE: François Borella, Les parties politiques dans l'Europe des Neuf, Ed. d Seuil, 1979; G. Sartori, Parties and Party Systems, Cambridge, 1976; S. Henig, J. Pinder, Partidos politicos europeos, Edersa, 1976; "II Corriere della Sera», 12 de junio de 1979. 
ELECCIONES LEGISLATIVAS AL SENADO EN ITALIA

\begin{tabular}{|c|c|c|c|c|c|c|c|c|c|c|c|c|c|c|}
\hline SEnado & $\begin{array}{l}\text { Radi- } \\
\text { cales }\end{array}$ & PCI & PCI-PSI & PSI & PSDI & PRI & $\begin{array}{l}\text { PSDI- } \\
\text { PRI- } \\
\text { PLI }\end{array}$ & DCI & PLI & MSI & SVP & $\begin{array}{c}\text { Valdos- } \\
\text { tani }\end{array}$ & Otros & Total \\
\hline $1976 \%$ & 0,8 & 33,8 & 0,2 & 10,2 & 3,1 & 2,7 & 1,1 & 38,9 & 1,4 & 6,6 & 0,5 & 0,1 & 0,6 & 100 \\
\hline Esc. & 0 & 116 & 1 & 29 & 6 & 6 & 2 & 135 & 2 & 15 & 2 & 1 & 0 & 315 \\
\hline 1979 & $\begin{array}{c}1,3 \\
2\end{array}$ & $\begin{array}{l}31,5 \\
109\end{array}$ & - & $\begin{array}{c}10,4 \\
32\end{array}$ & $\begin{array}{c}4,2 \\
9\end{array}$ & $\begin{array}{c}3,4 \\
6\end{array}$ & - & $\begin{array}{l}38,3 \\
138\end{array}$ & $\begin{array}{c}2,2 \\
2\end{array}$ & $\begin{array}{l}5,7 \\
13\end{array}$ & $\begin{array}{c}0,5 \\
3\end{array}$ & $\begin{array}{c}0,1 \\
1\end{array}$ & $\begin{array}{c}2,4 \\
0\end{array}$ & $\begin{array}{l}100 \\
315\end{array}$ \\
\hline
\end{tabular}

FUENTE: «Il Corriere della Sera», 12 de junio de 1979. 